\title{
Anchoring Effects in the HRS: \\ Experimental and Nonexperimental Evidence
}

by

Michael D. Hurd

\author{
RAND \\ SUNY, Stony Brook \\ NBER
}

October, 1997

Financial support from the National Institute on Aging through a grant to the National Bureau of Economic Research is gratefully acknowledged. 


\section{ABSTRACT}

"Anchoring Effects in the HRS: Experimental and Nonexperimental Evidence"

The Health and Retirement Study (HRS) and a number of other major household surveys use unfolding brackets to reduce item nonresponse. However, the initial entry point into a bracketing sequence is likely to act as an anchor or point of reference to the respondent: The distribution of responses among those bracketed would be influenced by the entry point. For example, when the initial entry point is high the distribution will be shifted to the right, leading one to believe that holdings of the particular asset are greater than they truly are. This paper has two goals. The first is to analyze some experimental data on housing value from HRS wave 3 for anchoring effects. The second is to compare the distributions of assets in HRS waves 1 and 2 for evidence about any anchoring effects that may have been caused by changes in the entry points between the waves. Both the experimental data on housing values and the nonexperimental data from HRS waves 1 and 2 on assets show anchoring effects. The conclusion is that to estimate accurately wealth change in panel data sets, we need a method of correcting for anchoring effects such as random entry into the bracketing sequence.

Michael D. Hurd RAND Corporation 1700 Main Street Santa Monica, CA 90401 mhurd@rand.org 


\section{Introduction}

Item nonresponse in a survey is the failure of a respondent to answer a question fully. In household surveys, item nonresponse to questions about income, and particularly assets can be rather high: for example in the 1991 Survey of Income and Program Participation $47 \%$ of married respondents who owned common stock did not give a value for their stock holdings, and 66\% of single respondents did not give a value (Hoynes, Hurd and Chand, forthcoming). Because of the highly skewed distribution of many assets, imputation for missing values is not very satisfactory: covariates can explain a rather small fraction of variance, which means that, the true stock holdings of a household are likely to be far from the imputed value.'

The Health and Retirement Study (HRS) and the Asset and Health Dynamics Study (AHEAD), and a number of other major household surveys use bracketing to reduce the harm to data quality from item nonresponse. In a typical bracketing sequence, a respondent will be asked about ownership of an asset such as common stocks. At this stage the response rate is very high, for example $98.1 \%$ in the AHEAD baseline. However, when owners of stocks are asked to give the value of their holdings, the response rate falls substantially: in AHEAD among owners of stocks just $54 \%$ gave a value to their stock holdings, or, in terms of nonresponse, $46 \%$ either refused to answer (RF) or did not know the value (DK). In HRS and AHEAD the nonrespondents were then asked a series of bracketing questions, which because these surveys are mainly administered over the telephone, are in the form of "unfolding" bracketing questions. For example, in wave 1 of HRS a respondent who answered RF or DK to the question about stock value was asked "Would it amount to $\$ 25,000$ or more?" If "yes," "Would it amount to $\$ 100,000$ or more?" and so forth until the value of the asset was placed in one of the brackets O-\$4,999, $\$ 5,000-\$ 24,999, \$ 25,000-99,999, \$ 100,000-\$ 499,999$ or $\$ 500,000$ or more. Of course, knowing the bracket in which the value lies is not as good as knowing the actual value, but knowledge of the bracket can substantially improve the

\footnotetext{
${ }^{1}$ While stochastic imputation can preserve the distribution of responses, it would not improve imputation for a particular household.
} 
accuracy of imputation. For example, using the bracket information only for imputation typically yields an $\mathrm{R}^{2}$ of about 0.80 in $\log$ s whereas covariates alone would yield an $\mathrm{R}^{2}$ of about 0.20 . Therefore, even a simply hot-deck imputation within brackets would give much better individual imputations than could be obtained without the brackets. The imputation can be further improved by using covariates in addition as in "nearest neighbor" imputation (Little, Sande and Scheuren, 1988; Hoynes, Hurd and Chand, forthcoming).

Despite the utility of using unfolding brackets, however, the initial entry point into the bracketing sequence is likely to act as an anchor or point of reference to the respondent, and work by psychologists suggests that the distribution of responses among those bracketed would be influenced by the entry point. ${ }^{2}$ When the initial entry point is high the distribution will be shifted to the right, leading one to believe that holdings of the particular asset are greater than they truly are. A seemingly plausible method of investigating anchoring effects based on the data from waves 1 of HRS and AHEAD would be to compare for each asset the distribution of responses among those that gave a continuous response (actual value) with the distribution among those that were bracketed. Evidence for anchoring effects would be that the distribution of the bracketed responses is systematically shifted to the right when the entry point is high relative the distribution of the continuous responses. For example, anchoring would predict that when the entry point is greater than the median of the continuous responses, the median of the bracketed responses will be greater than the median of the continuous responses. However, there is good evidence that self-selection into the bracketing sequence affects the estimated distribution: in particular respondents that answered RF have different characteristics than the continuous respondents, and they seem truly to have higher asset holdings (Smith, 1995). Thus the effects of anchoring and the effects of selection are confounded.

Between wave 1 and wave 2 of HRS many of the brackets were changed through a procedure called "bracket optimization." The aim of the procedure is to choose the best bracket boundary points where "best" is defined by the objective of maximizing a fitted

\footnotetext{
${ }^{2}$ See Tversky and Kahneman (1974), Kruglanski and Freund (1982), Jacowitz and Kahneman (1995), Strack and Mussweiler (1997), and Wilson, et al. (1996).
} 
sum of squares in imputation. Because of the highly skewed distributions of many assets the procedure often called for increasing the top boundary point so that few observations would be in the open interval $(\$ 500,000$ or over in the case of stocks in wave 1$)$, and in turn changing the other boundary points. In that one of the bracket boundary points serves as the entry point into the bracketing sequence, this meant in a number of cases the entry point was also changed. Furthermore, true holdings of many assets changed, mostly increasing, because of advances in capital markets, saving by households, and increased ownership rates. This by itself changed the relationship between the anchors and the distributions of the assets, which would be expected to cause the magnitudes of anchoring effects to change even had the entry points remained constant.

To provide data with which to study the effects of anchoring in surveys of economic data, two experiments were designed and conducted in the HRS and AHEAD studies. In AHEAD wave 2 subjects were queried about the value of savings accounts and the value of monthly consumption. They were randomly assigned to different entry puints in a bracketing sequence with the objective of finding the change in the distribution of responses as the entry point varied. The data show a substantial amount of anchoring: the median of estimated monthly consumption varied from about $\$ 860$ to $\$ 1490$ as the entry point varied from $\$ 500$ to $\$ 5000$. There was somewhat smaller variation in savings account balances probably reflecting less uncertainty among respondents (Hurd, $e t$ al. forthcoming).

HRS wave 3 contained some randomized experiments about housing value, about regular checking accounts and about the circumference of the earth with the same objectives. Because of the random assignment, there should be no systematic effects of self-selection.

This paper has two goals. The first is to analyze the experimental data on housing value from HRS wave 3 for anchoring effects. Because some respondents are known a priori to have greater knowledge of housing value than others, one can find how anchoring varies with the level of uncertainty. The second goal is to compare the distributions of assets in HRS waves 1 and 2 for evidence about the effects of the changes in the entry points between the waves. 
2. Anchoring experiments in HRS wave 3

The HRS is biennial panel. At baseline in 1992 it surveyed 12,654 communitydwelling persons in the U.S. representing the cohorts of 1931-1941 and their spouses. Its main substantive domains are labor market behavior, health and economic status. It placed particular emphasis on a complete inventory of income and assets and their careful measurement.

To encourage innovation the HRS has added experimental modules at the end of each wave of the main survey. The experimental modules have the aim of administering 2-3 minutes of speculative, experimental or one-shot material that, if successful, could be put on the main survey. They are asked at end of interview, and the respondents are given the specific opportunity to refuse. However, the refusal rate to the modules is low. The anchoring experiments in HRS wave 3 were in the experimental modules.

Wave 3 was administered in 1996, when the age-eligible respondents would have been about 55-65. There were three categories of questions on the experimental modules about anchoring: the value of owner occupied housing, value of regular checking accounts and the circumference of the earth. Respondents were not allowed to give a continuous answer but were asked unfolding bracket questions. I will use data here from nine modules on 7387 individuals about housing value.

Following an initial question that ascertained ownership, owners were asked about housing value in one of three formats:

\footnotetext{
"Would it be more than $\$ \$ \$ ? "$

"Would it be $\$ \$$ or more?"

"Would it be less than $\$ \$ \$$ or more than $\$ \$ \$ ? "$
}

where $\$ \$ \$$ was one of $\$ 50 \mathrm{k}, \$ 100 \mathrm{k}, \$ 150 \mathrm{k}$. The purpose of the variation in question format was to investigate whether the unbalanced formats (the first two) cause the distribution of responses to be shifted to the right (higher values). Apparently 
psychological experiments find that people tend to answer "yes" to questions somewhat more often than "no," even when through randomization there should be no difference in the frequencies. Such an effect would, for these formats, lead to greater frequencies in the higher brackets compared with the balanced format and, therefore, higher imputed housing values.

The experimental design called for interactions among all the treatments, so that there were nine treatments. Individuals were assigned at random to one of the treatments. The importance of assignment by individual rather than by household is that the question about housing value had already been answered in the main survey by the financial respondent.' Because anchoring effects are thought to increase with the uncertainty of the respondent, we would expect little if any anchoring effects among financial respondents regardless of the accuracy of their knowledge of housing values: they simply had to remember the answer they gave a short time earlier in the survey and accurately bracket themselves. We would expect moderate amounts among nonfinancial respondents because most people probably have a good, but not certain, idea of housing value.

Figure 1 shows the distribution of responses among financial respondents when the question format was "Would it be more than $\$ \$ \$$ ?" The figure shows the percentage distribution at the points $\$ 50 \mathrm{k}$ (first panel), $\$ 100 \mathrm{k}$ (second panel), and $\$ 150 \mathrm{k}$ (third panel) as a function of the entry point (anchor). For example, when the anchor was $\$ 50 \mathrm{k}$, about $19 \%$ of the financial respondents answered "no" to the question "Would it be more than $\$ \$ \$$ ?" and therefore were placed in the interval less than or equal to $\$ 50 \mathrm{k}$. Among those given the initial entry point of $\$ 100 \mathrm{k}$, about $58 \%$ answered "no" (second panel) and about $17 \%$ of the total answered "no" when given the follow-up question "Would it be more than $\$ 50 \mathrm{k}$ ?" (first panel). Evidence of anchoring would be that the distribution shifts to the right as the anchor increases, or in the figure the percentage at any point decreases as the anchor increases. For example, the percentage having $\$ 100 \mathrm{k}$ or less should decrease as the entry point increases from $\$ 50 \mathrm{k}$ to $\$ 100 \mathrm{k}$ to $\$ 150 \mathrm{k}$. The right-most panel has that pattern, but the other two panels do not. Thus, Figure 1 has no overall evidence that the

\footnotetext{
${ }^{3}$ The financial respondent is the spouse that is judged by the respondents themselves to be most knowledgeable about the financial situation of the household.
} 
financial respondents were anchored. The results are about the same for the format “Would it be $\$ \$$ or more?" so I do not show them.

Figure 2 shows the distributions when the format is "Would it be less than $\$ \$ \$$ or more than $\$ \$ \$$ ?" The vertical segments come from voluntary answers. For example, a respondent when given the initial entry of $\$ 100 \mathrm{k}$ might volunteer that the value is about $\$ 100 \mathrm{k}$. Thus there is a probability mass at $\$ 100 \mathrm{k}$ which causes the jump. This is a valuable feature of the balanced question: in imputation such respondents could be imputed a value of $\$ 100 \mathrm{k}$ rather than a random draw from the interval $\$ 50 \mathrm{k}$ to $\$ 100 \mathrm{k}$ or from $\$ 100 \mathrm{k}$ to $\$ 150 \mathrm{k}$. The figure does not show any consistent anchoring effect: the distribution for the entry point of $\$ 100 \mathrm{k}$ is shifted to the left of the distributions for $\$ 50 \mathrm{k}$ and $\$ 150 \mathrm{k}$, which are about the same. 1 conclude that there is no consistent evidence for anchoring among financial respondents. As previously mentioned, this would be expected.

Figure 3 shows the distributions for nonfinancial respondents for the unbalanced question format, "Would it be more than $\$ \$ \$$ ?" and Figure 4 the distributions for the unbalanced format, "Would it be $\$ \$ \$$ or more?" Particularly in Figure 4 there is considerable evidence for an anchoring effect: when the entry was $\$ 50 \mathrm{k}$ about $50 \%$ said their housing value was less than $\$ 100 \mathrm{k}$; when the entry was $\$ 150 \mathrm{k}$ only about $38 \%$ said it was less than $\$ 100 \mathrm{k}$. The effect seems to be greatest when the anchor is increased from $\$ 100 \mathrm{k}$ to $\$ 150 \mathrm{k}$ rather than from $\$ 50 \mathrm{k}$ to $\$ 100 \mathrm{k}$.

Figure 5 has the distributions for the balanced format among nonfinancial respondents. When the entry was $\$ 50 \mathrm{k}$ or $\$ 100 \mathrm{k}$ the distributions were about the same with an estimated median of about $\$ 90 \mathrm{k}$. However, the distribution was shifted substantially to the right when the entry was $\$ 150 \mathrm{k}$, and the estimated median increased to about $\$ 100 \mathrm{k}$, an increase of $11 \% .^{4}$

A way to summarize the nine treatments is by descriptive regression. The lefthand variable in the regression is the estimated probability that housing value is less than $\mathrm{x}$, or that housing value is less than or equal to $x$, where $\mathrm{x}=\$ 50 \mathrm{k}, \$ 100 \mathrm{k}, \$ 150 \mathrm{k}$. The right hand variables are indicator variables for the probabilities, indicator variables for question

\footnotetext{
${ }^{4}$ The estimates of the medians are based on linear interpolation of the logs
} 
format, and indicator variables for the initial anchor interacted with an indicator variable for financial respondent. ${ }^{5}$

Table 1 has the results of the regression. Negative coefficients mean that relative to the reference group, the probability that housing value is less than or less than or equal to $\mathrm{x}$ is lower. That is, the distribution is shifted to the right toward higher values. The table shows that, indeed, question format has an effect on the distributions of responses, and the effect is what would be predicted: when the format is unbalanced there is a reduction in the fraction that are bracketed below any of the points $\$ 50 \mathrm{k}, \$ 100 \mathrm{k}$ or $\$ 150 \mathrm{k}$, or said differently, a greater fraction end up in the higher brackets.

The financial respondent has a somewhat higher probability of bracketing into the lower brackets as indicated by comparing the coefficients on financial respondent with the coefficients on nonfinancial respondent, holding constant the anchor point. For example, the financial respondent has about a 0.04 higher probability of being bracketed below $\$ 50 \mathrm{k}, \$ 100 \mathrm{k}$ or $\$ 150 \mathrm{k}$ when the initial entry point is $\$ 100 \mathrm{k}$ compared with the nonfinancial respondent. The financial respondent would be imputed with lower housing values than the nonfinancial respondent. This happens because all nonfinancial respondents are married whereas some financial respondents are single. Because couples have higher housing value than singles, on average nonfinancial respondents have higher housing values than financial respondents. ${ }^{6}$

Anchoring effects are indicated by increasingly negative coefficients as the anchor point increases. It is evident that for financial respondents there are no anchoring effects. For nonfinancial respondents, however, the probability decreases by 0.05 when the anchor increases from $\$ 50 \mathrm{k}$ to $\$ 150 \mathrm{k}$, almost completely due to change when the entry increases from $\$ 100 \mathrm{k}$ to $\$ 150 \mathrm{k}$. To show the importance of this effect, Figure 6 has fitted distributions for three cases: an average financial respondent (averaged over the three anchor points), a nonfinancial respondent with anchor of $\$ 100 \mathrm{k}$ and a nonfinancial respondent with anchor of $\$ 150 \mathrm{k}$. As before the vertical segments result from voluntary responses to the balanced questions. The estimated median among the financial

\footnotetext{
${ }^{5}$ The probability variables are indicators that housing value is $<\$ 50 \mathrm{k}, \leq \$ 50 \mathrm{k},<\$ 100 \mathrm{k}, \leq \$ 100 \mathrm{k},<$ $\$ 150 \mathrm{k}$, and $\leq \$ 150 \mathrm{k}$.

${ }^{6}$ Thanks to Martha Hill for pointing this out to me.
} 
respondents is about $\$ 87 \mathrm{k}$, which is very close to the "true" median from the main survey of $\$ 90 \mathrm{k}$. Among nonfinancial respondents the medians are about $\$ 92 \mathrm{k}$ and $\$ 100 \mathrm{k}$. Thus increasing the anchor by $50 \%$ (from $\$ 100 \mathrm{k}$ to $\$ 150 \mathrm{k}$ ) increased the median among nonfinancial respondents by about $8.7 \%$ which is an elasticity of $17.4 \%$.

One conclusion from this experiment is that question format influences the distribution of responses: the unbalanced format led to higher frequencies of affirmative responses, and, in the context of this experiment, higher implicit housing values. A second conclusion is that the magnitude of anchoring varies with the amount of uncertainty. Financial respondents are likely to have better knowledge of housing value than nonfinancial respondents; but more importantly financial respondents earlier in the survey had given their estimate of housing value, which apparently resolved any uncertainty about their estimates. Indeed, financial respondents were not anchored whereas nonfinancial respondents were moderately anchored.

3. Asset change between waves 1 and 2

Between waves 1 and 2 of HRS there were a number of changes that would affect measured asset holdings. True holdings of many assets changed, mostly increasing, because of advances in capital markets, saving by households, and increased ownership rates. There may have been an increase in the level of uncertainty because of the rapid change in the prices of assets. The bracket optimization program changed many of the brackets and the entry points, so that any anchoring effects would have changed. There may have been a change in the importance of self-selection. The data are not adequate to investigate all of these changes. I will assume for the moment that the relative magnitude of self-selection did not change between the waves; however, this assumption is not really necessary to find at least qualitatively if there were anchoring effects induced by the changes in the entry points. 
Table 2 shows the rate of asset ownership in each wave, and among owners the distribution of types of answers about the value of the asset. ${ }^{7}$ For example, $27.1 \%$ of households owned stocks in wave 1 . Among the owners, $73.1 \%$ gave a continuous response (actual number) to the query about value, $20.9 \%$ were bracketed and $6 \%$ did not give a continuous answer and would not answer the bracketing questions. The number bracketed was 459 .

Ownership rates were rather stable, with modest increases in stocks and IRAs and modest declines in certificates of deposit and treasury bills. The rate of continuous responses declined for about half of the asset categories. Some of this decline is due to the use of the range card in wave 1: the interview in wave 1 was face-to-face which allowed some respondents who refused to give a continuous amount to give a bracket interval from a range card. The bracket intervals in the range card were different from the bracket intervals in the unfolding brackets. Furthermore, there is no comparable entry point which would act as an anchor, so that a meaningful comparison with wave 2 bracketed responses cannot be made.' For this reason I treated range card respondents in wave 1 as continuous responses.' The percentage refusing to give a bracket generally declined between the waves, possible reflecting increased confidence among respondents in the survey.

Table 3 shows the bracket boundaries and the entry points (shaded) for the eight asset categories." In a number of cases the upper boundary was increased so that fewer households would fall in the open-ended bracket. The initial entry point changed substantially for a number of assets including checking and saving, and certificates of deposit and treasury bills.

Separately by asset category, by wave and by bracket, the bracketed observations were imputed by hot-deck. That is, an asset value was assigned to a bracketed respondent

\footnotetext{
${ }^{7}$ These rates are calculated as cross-sectional rates; thus, the sample composition differs in the two waves.

${ }^{8}$ The range card will, nonetheless act as an anchor because respondents tend to give answers from the middle of the categories. Thus the distribution of responses will differ as the range and boundaries of the brackets in the range card are varied.

According to Smith (1995) the percentage of respondents that used the range card varied from 0.4 (bonds) to 4.0 (checking).

${ }^{10}$ Housing value is not analyzed because it was not bracketed in wave 1 .
} 
by making a random drawing from the pool of continuous reporters in the same bracket interval. On average the difference between the distributions of assets of the continuous reporters and the bracketed reporters is only due to the frequency of responses in each bracket. Table 4 has the median and mean in each wave for the eight asset categories.

In wave 1 the median value of common stocks among continuous reporters was $\$ 18$ thousand, and the entry point into the bracketing sequence was $\$ 25 \mathrm{k}$. If there were no selection, anchoring theory would suggest that the median among the bracketers would be greater than the median among continuous reporters because the anchor was greater than the median. This is found in the table. By wave 2, median stock holdings among continuous reporters grew to $\$ 26 \mathrm{k}$, but the entry point remained at $\$ 25 \mathrm{k}$. In that the anchor was approximately the same as the median, anchoring theory would suggest that the median among bracketers would not be affected by the anchor, and, therefore, it would be the same as the median among continuous reporters. This is also what the table shows. As a consequence the median among continuous reporters grew by $44 \%$ and among bracketers it grew by $25 \%$. The situation is similar for the mean.

The distribution of checking and savings accounts was very stable across waves as measured by the continuous reports: both the median and mean were unchanged at $\$ 5 \mathrm{k}$ and $\$ 16 \mathrm{k}$ respectively. However, the entry point increased from $\$ 5$ thousand to $\$ 50$ thousand: the median of the bracketers doubled and the mean increased by $43 \%$, suggesting substantial anchoring effects. The situation is similar for certificates of deposit and treasure bills.

The anchor point for bonds decreased between the waves, and although the continuous median and mean increased substantially, the bracketed median and mean were practically unchanged. The results for common stocks shoed that a shift in the distribution with a constant anchor would cause the bracketed median to increase, but by less than for continuous reporters. With bonds the anchor decreased substantially, apparently causing the net effect to be small.

For these four categories of assets the pattern is the same: if the entry point increased more that the increase in the median among continuous reporters both the median and the mean among the bracketers increased more than among the continuous 
reporters; if it increased by less the median and mean increased by less. For holdings of IRAs, real estate, business and transportation there are some violations of this pattern. For example, mean IRA holdings increased by $22 \%$ among continuous reporters, but by $33 \%$ among bracketers even though the anchor remained constant. There is a similar violation of the pattern for mean real estate value, and for business value.

There is no suggestion of an anchoring effect for transportation holdings, possibly reflecting greater knowledge among respondents about the value of their automobiles.

Figures 7 and 8 summarize these results. Each shows the percentage change in the bracketed amount minus the percentage change in the continuous amount as a function of the percentage change in the anchor. For example, the point $(400,100)$ in Figure 7 represents the median of CDs and T-bills: the anchor increased by $400 \%$, the median among bracketers increased by $100 \%$ and the median among continuous reporters increased by $0 \%$. If the effect of self-selection remains the same between the waves the difference in the change should reflect a change in the anchor." The figures generally show an increase in the difference as the increase in the anchor is greater. However, the effect does not appear to be linear: very large increases in the anchor seem to have little additional effect. This is in agreement with findings by Hurd, $e t$ al. (forthcoming) where very large anchors in the elicitation of savings accounts had less effect than large anchors. The implication is that an anchor must have some plausibility to have an effect.

The figures also have a fitted line from the regression of the difference in the change on the change in the anchor. The interpretation of the slope is the elasticity of the bracketed median or mean with respect to the anchor. Although the regression should only be considered to be data descriptive because the anchoring effects are likely to vary by asset type, the overall finding is within the general range that comes out of the experiments on AHEAD wave 2, and it is close to the elasticity of responses about housing value among nonfinancial respondents reported earlier. Furthermore, the regression shows a systematic relationship between the change in the anchor and the differential change in the medians and means that cannot be explained by a change in self-

\footnotetext{
"The effect of selection is not likely to remain the same for both the median and mean, as one would expect that changes in the shape of the distribution would cause self-selection to have differential effects on the median and mean.
} 
selection between the waves: any such change in self-selection would affect the differential change, but there is not reason it should be associated with the change in the anchor. That is, change in self-selection would decrease the explanatory power of the anchor change by causing unexplained variation in the left-hand variable, but not the magnitude of the effect.

\section{Conclusion.}

Both the experimental data on housing values and the nonexperimental data on eight asset categories show anchoring effects. As indicated in the housing experiment, the effect seems to vary with the uncertainty of the respondent. If this result is confirmed by further analysis, it opens the way for direct measures of population uncertainty about measured quantities through anchoring experiments.

The anchoring effect apparently varies with the relationship between the anchor and the true distribution. In that both the distribution of an asset and the uncertainty about the value of the asset change over time, it is unlikely that the anchoring effect would be constant over time even were the anchor to remain constant. For example, the entry points for stocks and for IRAs were unchanged from wave 1 to wave 2; yet the medians among the continuous reporters increased by $44 \%$ and $40 \%$ respectively while the medians among the bracketers increased by $25 \%$ and $20 \%$. Under this interpretation the anchoring effect biased downward measured change in the values of these assets. However, these quantitative assessments for each separate asset rely on the assumption that the effects of self-selection remained constant, which is not likely to be the case for all measures of asset change. The only reliable method of separating out change in self-selection from change in anchoring is to have random entry into the bracketing sequence. 


\section{REFERENCES}

Hoynes, Hilary, Michael Hurd and Harish Chand, forthcoming, "Household Wealth of the Elderly under Alternative Imputation Procedures," in David Wise, ed., Inquiries in the Economics of Aging, Chicago: University of Chicago Press.

Hurd, Michael D., Dan McFadden, Harish Chand, Li Gan, Angela Merrill and Michael Roberts, forthcoming, "Consumption and Saving Balances of the Elderly: Experimental Evidence on Survey Response Bias," in D. Wise, ed., Frontiers in the Economics of Aging, Chicago: University of Chicago Press

Jacowitz, K. E., and Kahneman, D., 1995, "Measures of Anchoring in Estimation Tasks," Personality and Social Psychology Bulletin, 2 1: 1161-1 166.

Kruglanski, A. W., and T. Freund, 1982, "The Freezing and Unfreezing of Lay-inferences: Effects on Impressional Primacy, Ethnic Stereotyping, and Numerical Anchoring, Journal of Experimental Social Psychology, 19: 448-468.

Little, Roderick J., I. G. Sande, and Fritz Scheuren. 1988, "Missing-Data Adjustments in Large Surveys," Journal of Business and Economic-Statistics, 6(3), July 1988, pp. $117-131$.

Smith, James P., 1995, "Racial and Ethnic Differences in Wealth," Journal of Human Resources 30: S 158-S 183.

Strack, Fritz and Thomas Mussweiler, 1997, "Explaining the Enigmatic Anchoring Effect: Mechanisms of Selective Accessibility," Journal of Personality and Social Psychology, 73: 3: 437-446.

Tversky, A., and D. Kahneman, 1974, "Judgment Under Uncertainty: Heuristics and Biases," Science, 185: 1124-1 131.

Wilson, T. D., C. E. Houston, K. M. Etling and N. Brekke, 1996, “A New Look at Anchoring Effects: Basic Anchoring and Its Antecedents, Journal of Experimental Psychology: General, 125: 387-402. 


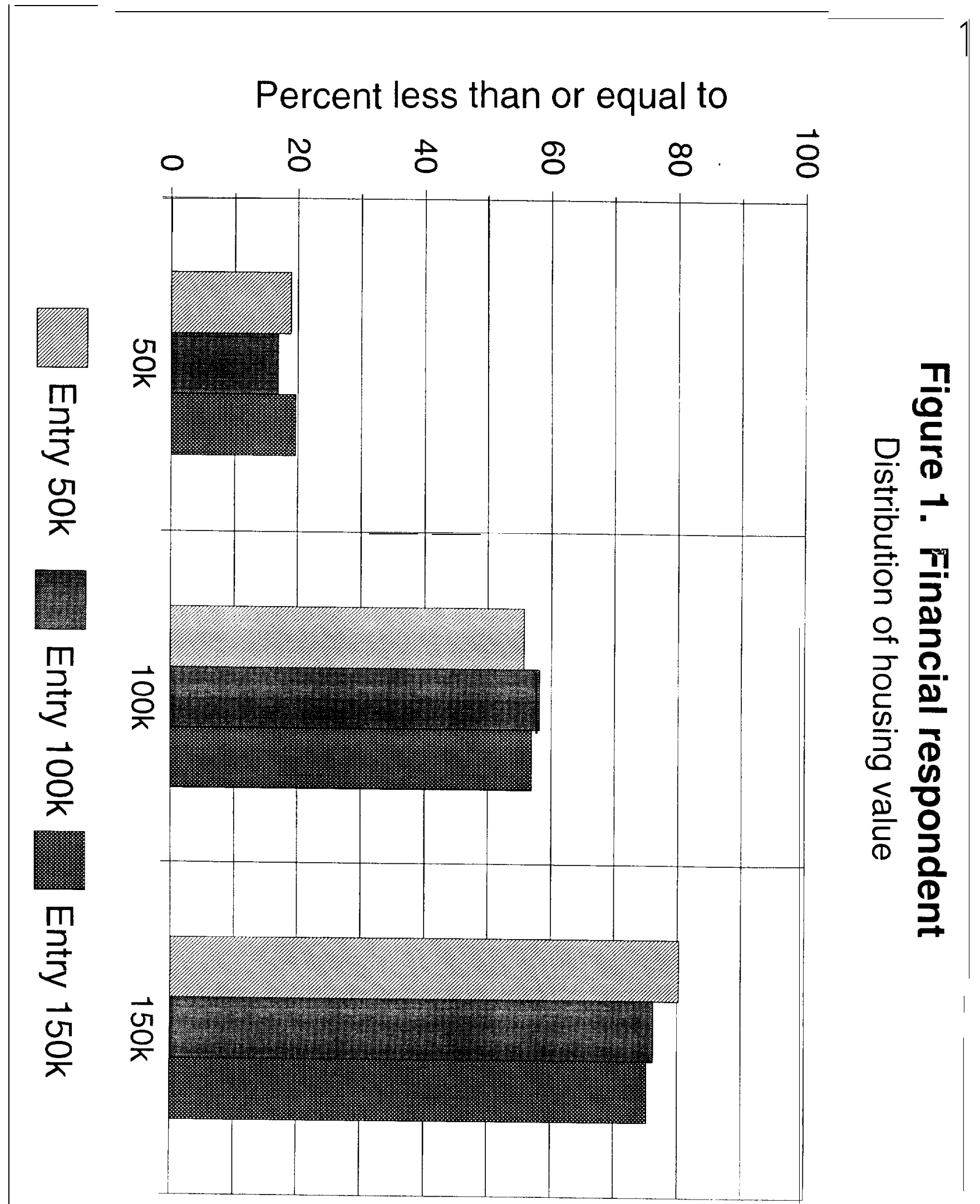




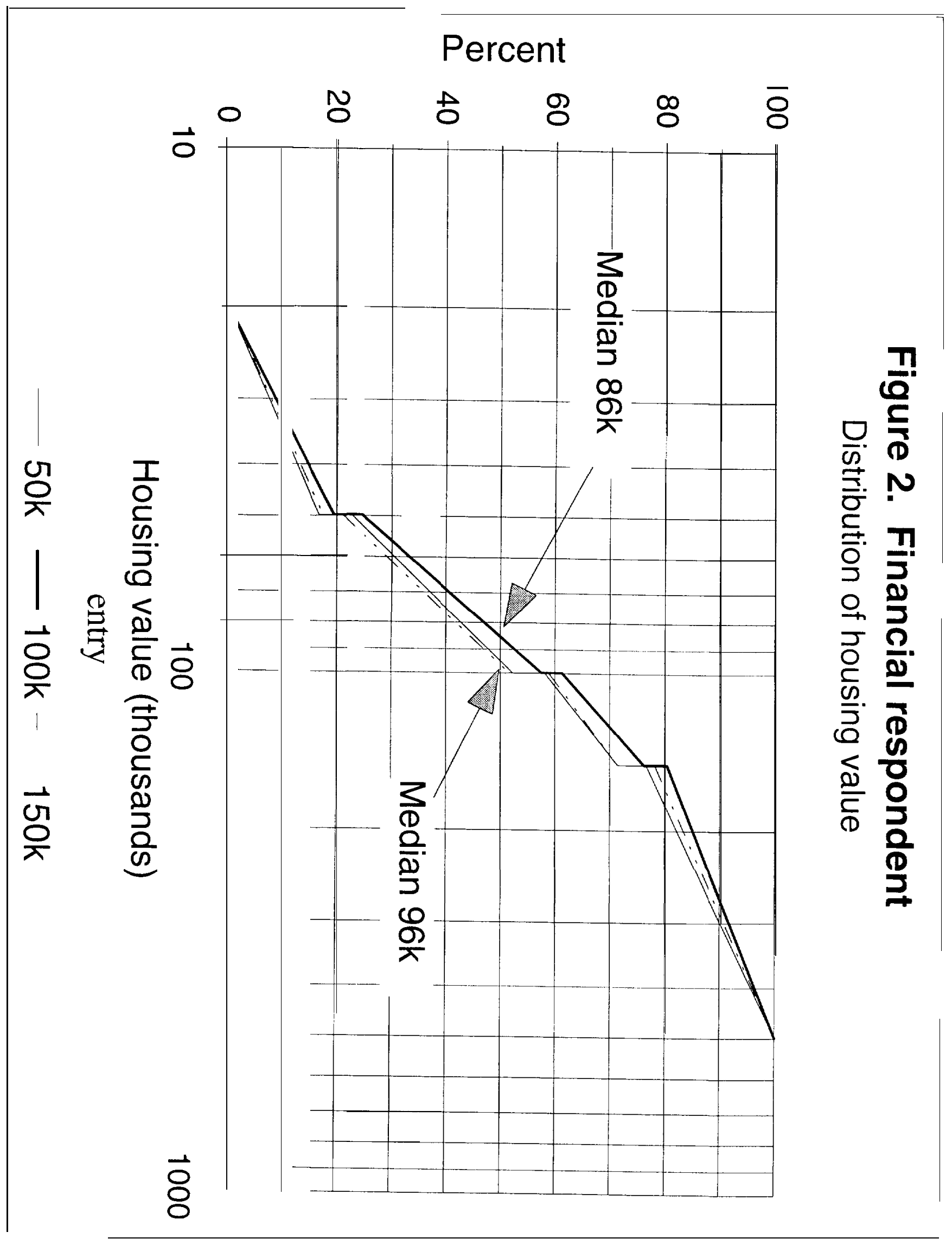




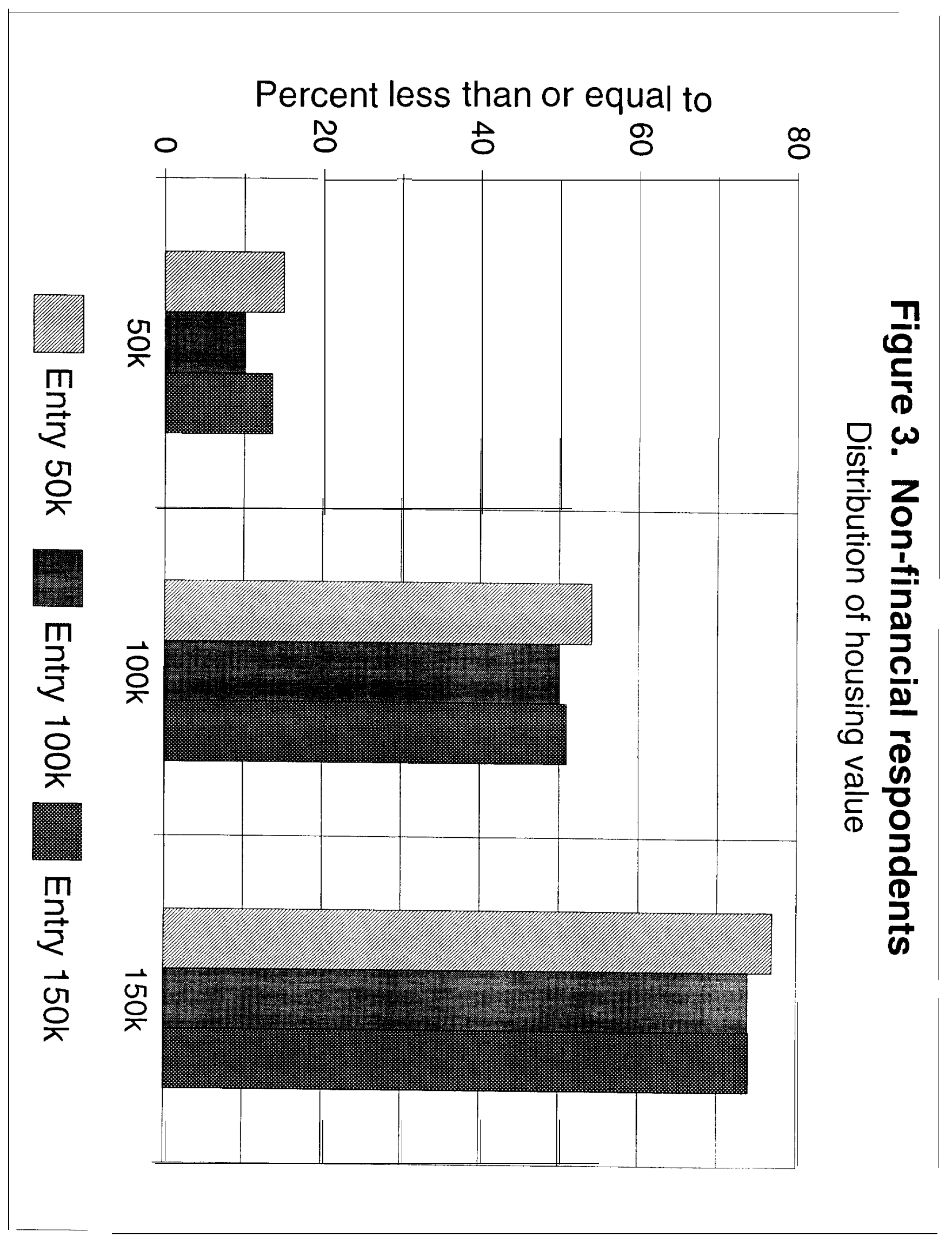




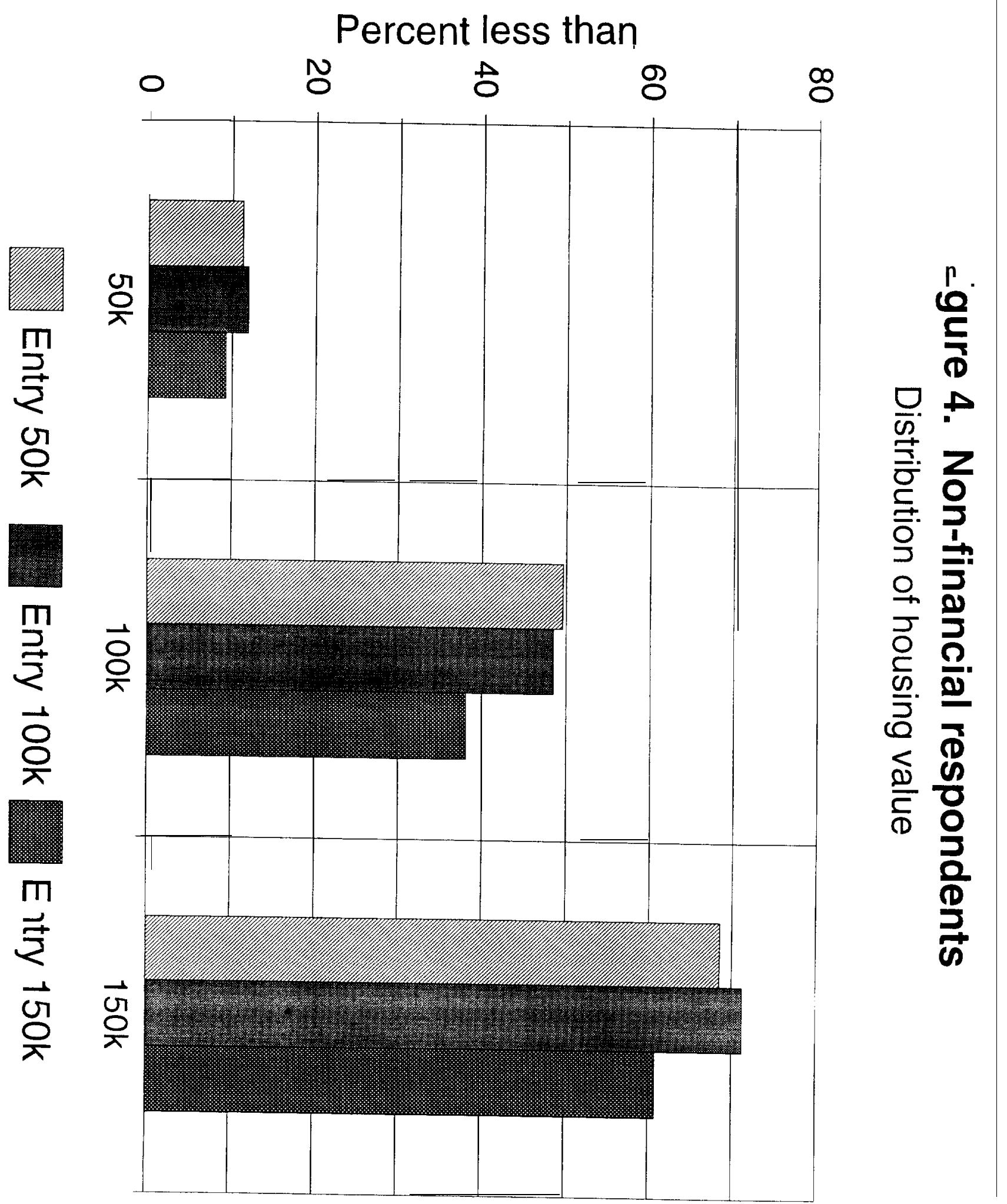




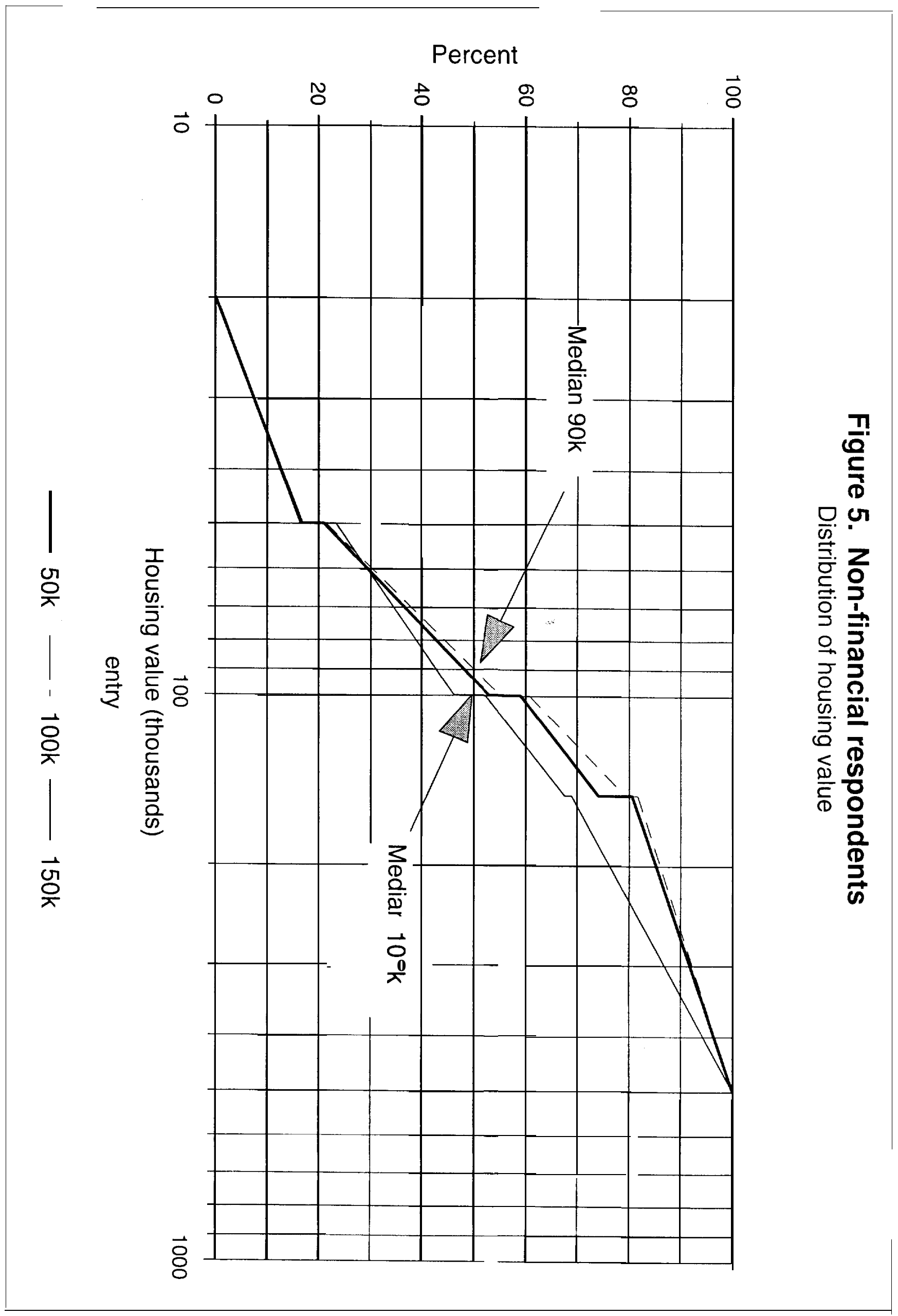




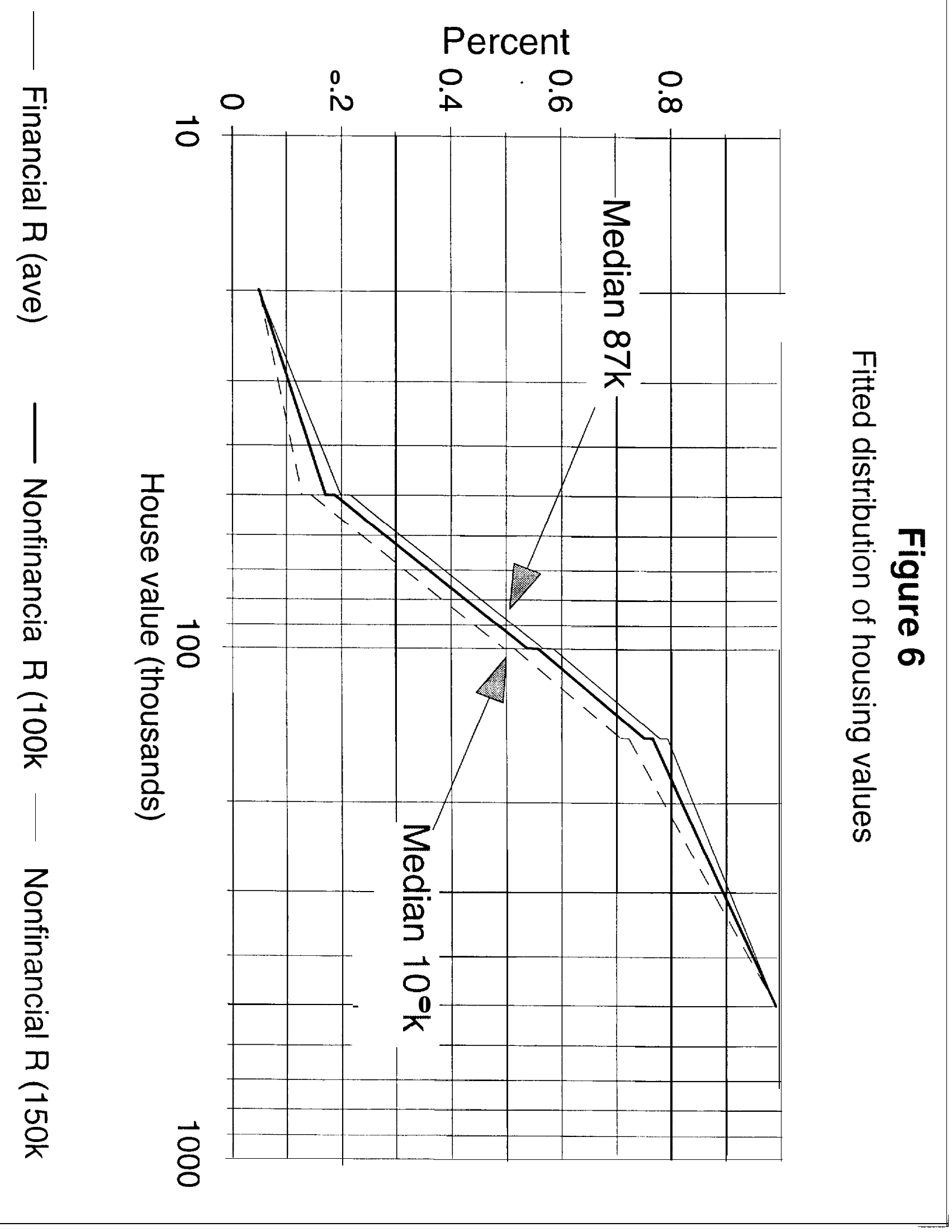




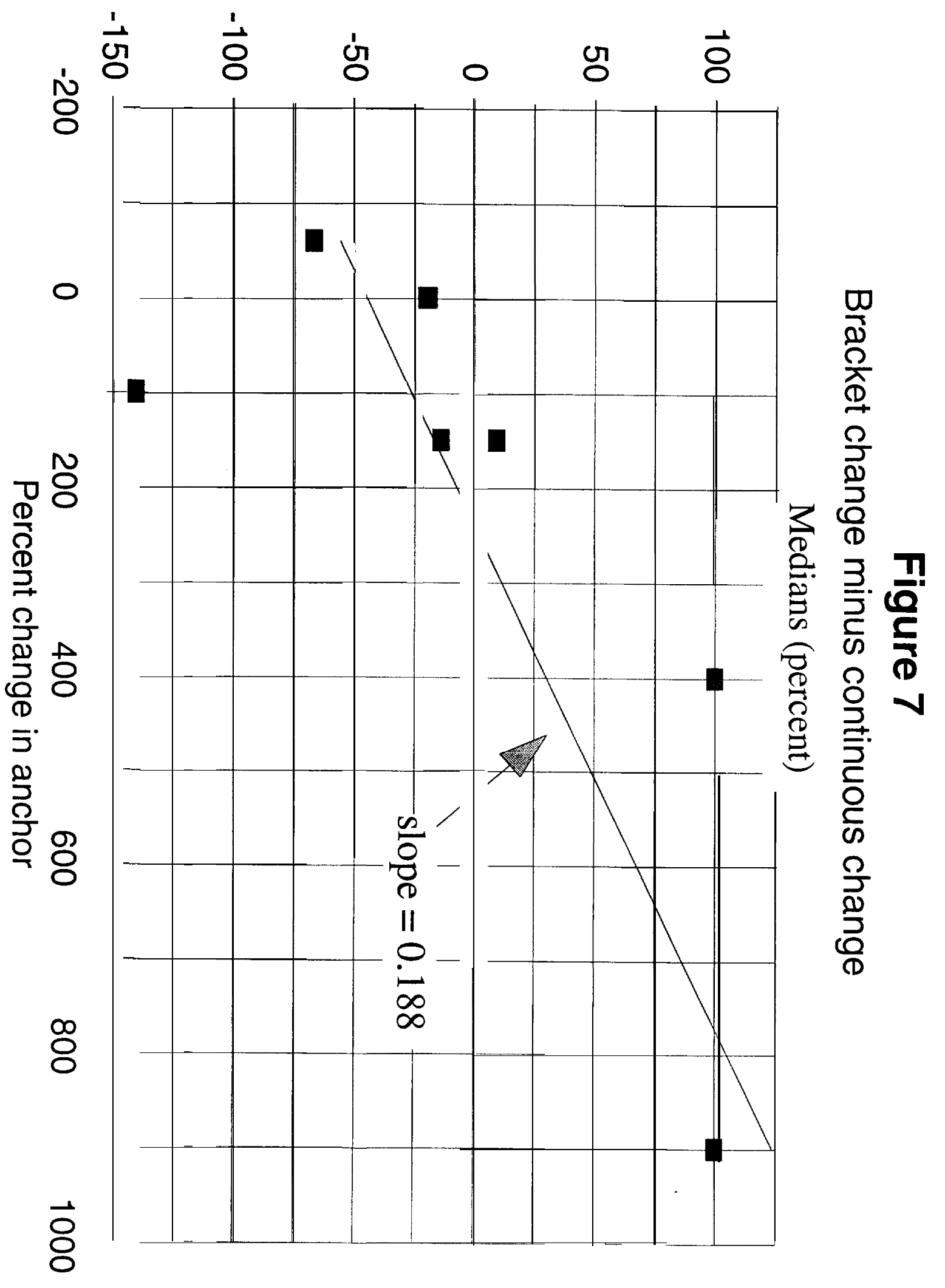




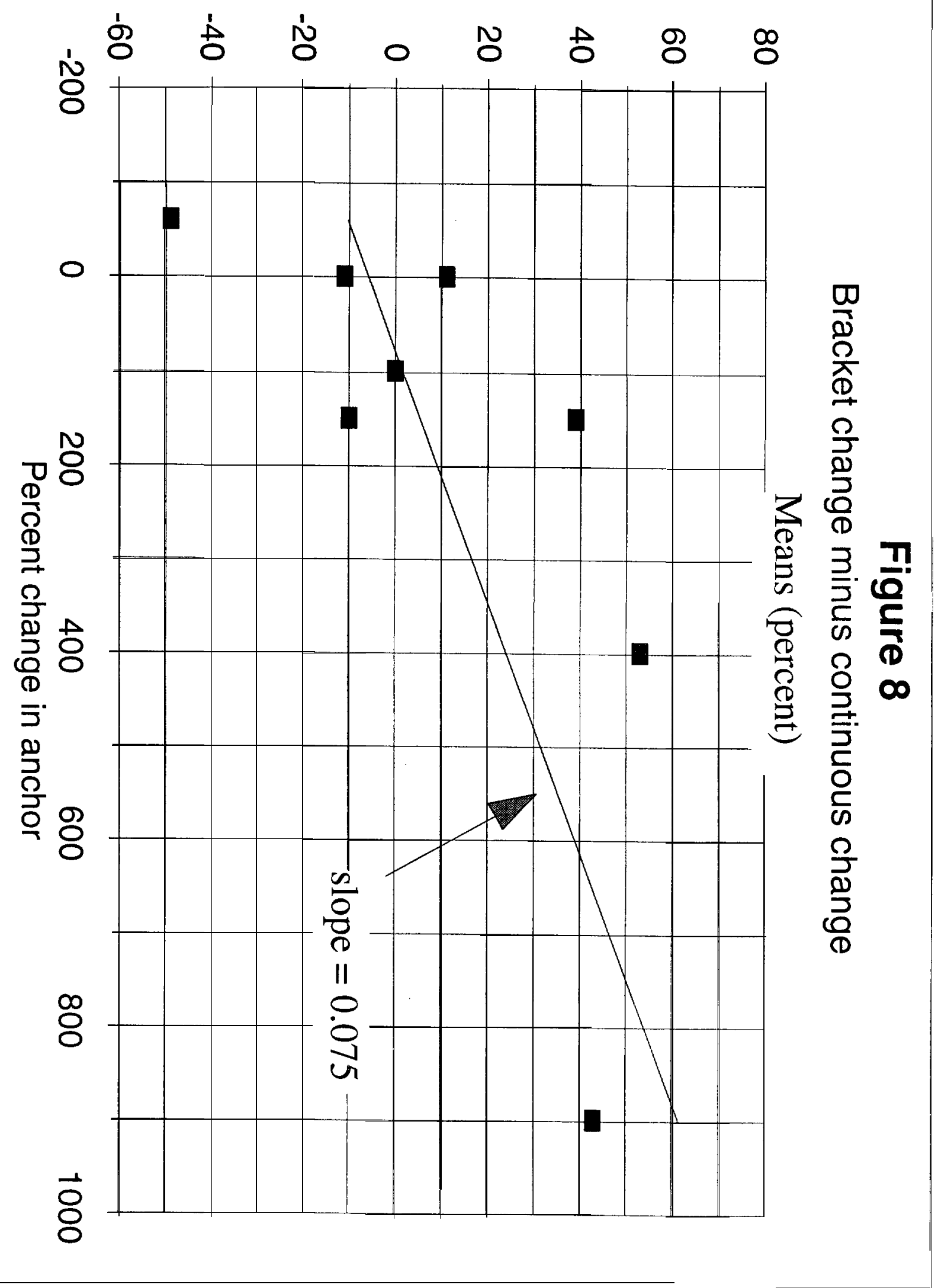


Table 1

Effects of question format, respondent type and entry point on the distribution of housing value

(probability-level indicators)

(see Figure 6)

Question format

Greater or less

Greater or equal

$-0.06$

Greater

$-0.02$

Respondent type and entry point

Not financial $\mathrm{R}$ and $50 \mathrm{k}$

0.01

Not financial R and $100 \mathrm{k}$

Not financial $\mathrm{R}$ and $150 \mathrm{k}$

$-0.04$

Financial $\mathrm{R}$ and $50 \mathrm{k}$

0.03

Financial R and $100 \mathrm{k}$

0.04

Financial $\mathrm{R}$ and $150 \mathrm{k}$

0.02

Source: Author's calculations based on HRS wave 3. Note: Positive numbers indicate left ward shift in distribution 
Table 2

Asset ownership rate and distribution of type of response about value of asset

\begin{tabular}{|c|c|c|c|c|c|c|}
\hline & \multirow[b]{2}{*}{$\%$ Owners } & \multicolumn{4}{|c|}{ Among owners (percent) } & \multirow[b]{2}{*}{$\begin{array}{l}\text { number } \\
\text { bracketec }\end{array}$} \\
\hline & & not bracketed & continuous & bracketed & total & \\
\hline \multicolumn{7}{|l|}{ Stocks } \\
\hline wave 1 & 27.1 & 6.0 & 73.1 & 20.9 & 100.0 & 459 \\
\hline uave2 & 30.2 & 5. 0 & 68.2 & 26.8 & 100.0 & 608 \\
\hline \multicolumn{7}{|l|}{ Checking } \\
\hline wave 1 & 78.9 & 5.1 & 79. 1 & 15.8 & 100.0 & 1003 \\
\hline wave 2 & 79.4 & 4.2 & 80.3 & 15.5 & 100.0 & 923 \\
\hline \multicolumn{7}{|c|}{ CDs, T-bills } \\
\hline wave 1 & 25.9 & 6.6 & 78. 1 & 15.3 & 100.0 & 320 \\
\hline wave 2 & 22.0 & 7.1 & 75.2 & 17.7 & 100.0 & 292 \\
\hline \multicolumn{7}{|l|}{ Bonds } \\
\hline uave 1 & 6.0 & 9.6 & 78.4 & 12.0 & 100.0 & 59 \\
\hline wave 2 & 5.3 & 9.9 & 70.9 & 19.2 & 100.0 & 76 \\
\hline \multicolumn{7}{|l|}{ I RAS } \\
\hline wave 1 & 37.9 & 5.1 & 79.1 & 15.8 & 100.0 & 486 \\
\hline wave2 & 40.9 & 3.5 & 77.1 & 19.4 & 100.0 & 597 \\
\hline \multicolumn{7}{|c|}{ Real estate } \\
\hline wave 1 & 24.3 & 3.5 & 80.3 & 16.2 & 100.0 & 320 \\
\hline nave2 & 25.2 & 2.2 & 79.3 & 18.5 & 100.0 & 349 \\
\hline \multicolumn{7}{|l|}{ Business } \\
\hline wave 1 & 16.7 & 5.2 & 70.4 & 24.4 & 100.0 & 330 \\
\hline wave 2 & 16.6 & 4.3 & 63.6 & 32.1 & 100.0 & 398 \\
\hline \multicolumn{7}{|c|}{ Transportation } \\
\hline wave 1 & 100.0 & 1.8 & 89.8 & 8.4 & 100.0 & 683 \\
\hline wave 2 & 99.6 & 0.8 & 91.2 & 8.0 & 100.0 & 604 \\
\hline
\end{tabular}


Table 3

Bracket boundaries and entry points (thousands)

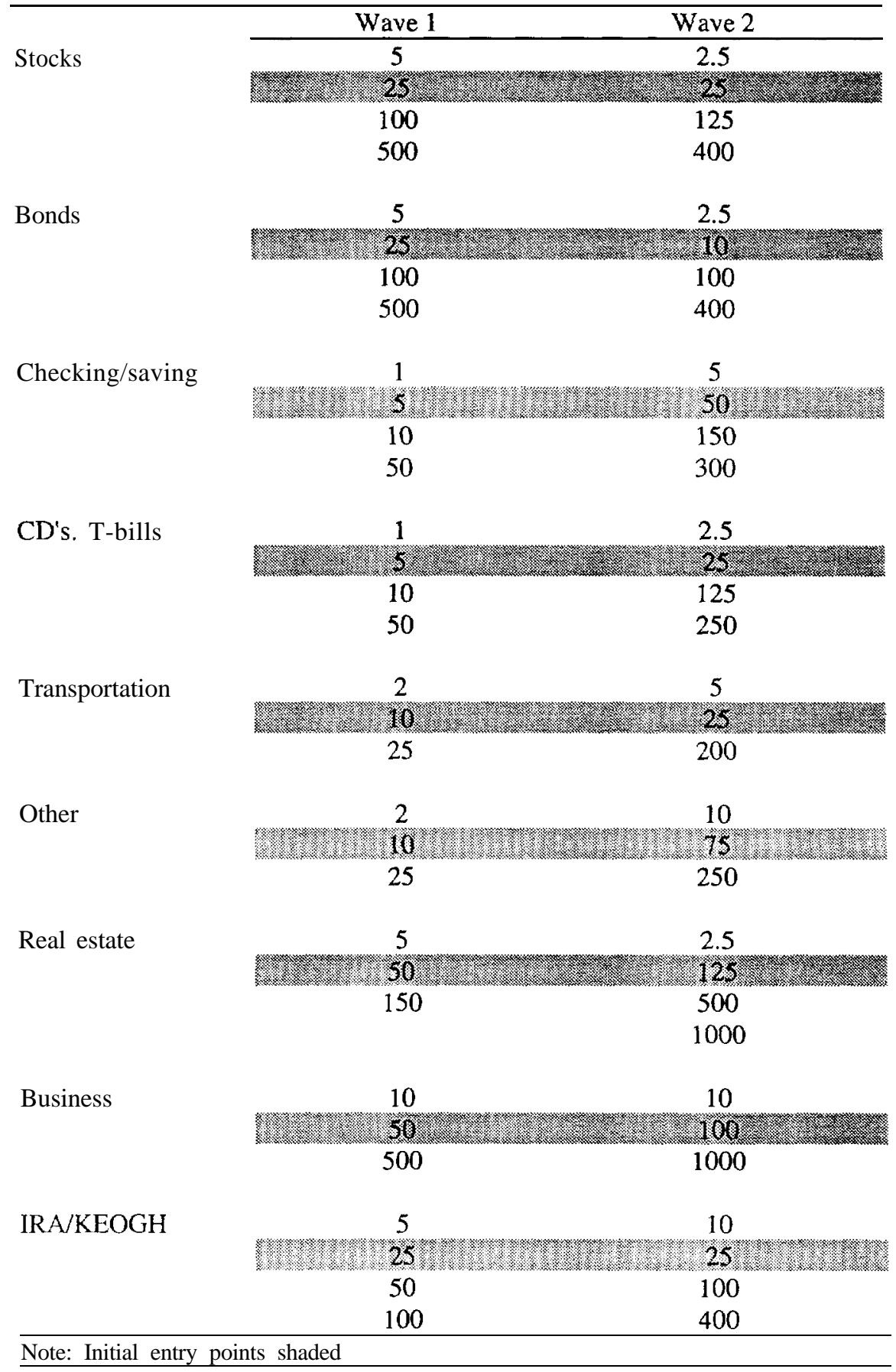


Table 4

Asset holdings by continuous reporters and bracketed reporters (thousands)

\begin{tabular}{|c|c|c|c|c|c|}
\hline & \multirow[b]{2}{*}{ Anchor } & \multicolumn{2}{|c|}{ Median } & \multicolumn{2}{|c|}{ Mean } \\
\hline & & Continuous & Bracketed & Continuous & Bracketed \\
\hline Stocks & & & & & \\
\hline wave 1 & 25 & 18 & 20 & 59 & 73 \\
\hline $\begin{array}{c}\text { wave } 2 \\
\text { Checking }\end{array}$ & 25 & 26 & 25 & 66 & 74 \\
\hline wave 1 & 5 & 5 & 5 & 16 & 21 \\
\hline $\begin{array}{l}\text { wave } 2 \\
\text { CDs, T-bills }\end{array}$ & 50 & 5 & 10 & 16 & 30 \\
\hline wave 1 & 5 & 8 & 10 & 27 & 45 \\
\hline $\begin{array}{l}\text { wave } 2 \\
\text { Bonds }\end{array}$ & 25 & 8 & 20 & 24 & 64 \\
\hline wave 1 & 25 & 12 & 20 & 48 & 73 \\
\hline $\begin{array}{l}\text { wave } 2 \\
\text { IRAs }\end{array}$ & 10 & 20 & 20 & 69 & 69 \\
\hline wave 1 & 25 & 20 & 25 & 45 & 45 \\
\hline $\begin{array}{l}\text { wave } 2 \\
\text { Real estate }\end{array}$ & 25 & 28 & 30 & 55 & 60 \\
\hline wave 1 & 50 & 45 & 75 & 149 & 219 \\
\hline wave 2 & 125 & 50 & 90 & 98 & 229 \\
\hline Business & & & & & \\
\hline wave 1 & 50 & 25 & 95 & 168 & 294 \\
\hline $\begin{array}{l}\text { wave } 2 \\
\text { Transportation }\end{array}$ & 100 & 55 & 75 & 112 & 197 \\
\hline wave 1 & 10 & 7 & 10 & 13 & 22 \\
\hline wave 2 & 25 & 8 & 10 & 12 & 18 \\
\hline
\end{tabular}

